\title{
Crop phenology and soil moisture applications of SCATSAT-1
}

\author{
Nilima R. Chaube ${ }^{1, *}$, Sasmita Chaurasia ${ }^{1}$, Rojalin Tripathy ${ }^{1}$, \\ Dharmendra Kumar Pandey ${ }^{1}$, Arundhati Misra ${ }^{1}$, B. K. Bhattacharya ${ }^{1}$, \\ Prakash Chauhan $^{2}$, Kiran Yarakulla ${ }^{3}$, G. D. Bairagi ${ }^{4}$, \\ Prashant Kumar Srivastava $^{5}$, Preeti Teheliani ${ }^{6}$ and S. S. Ray ${ }^{6}$ \\ ${ }^{1}$ Space Applications Centre, ISRO, Ahmedabad 380 015, India \\ ${ }^{2}$ Indian Institute of Remote Sensing, Dehradun 248 001, India \\ ${ }^{3}$ Vellore Institute of Technology, Vellore 632 014, India \\ ${ }^{4}$ M.P. Council of Science and Technology, Bhopal 462 003, India \\ ${ }^{5}$ Banaras Hindu University, Varanasi 221 005, India \\ ${ }^{6}$ Mahalanobis National Crop Forecast Centre, Delhi 110 012, India
}

SCATSAT-1 measures the backscattering coefficient over land surfaces, which is a function of vegetation structure, surface roughness, soil moisture content, incidence angle and dielectric properties of vegetation. Scatterometer image reconstruction techniques provide fine resolution data to explore the emerging applications over land by using ambiguous backscatter from land. In this paper, $2 \mathrm{~km}$ resolution products of ISRO's scatterometer SCATSAT-1 are exploited for land target detection, rice crop phenology stages detection for kharif and rabi seasons and estimation of relative soil moisture over parts of India. Temporal and spatial backscatter changes are due to seasonal and changes in Land Use Land Cover. Crop phenology stages such as transplanting, maximum tillering, panicle emergence and physiological maturity stages are identified by analysing SCATSAT-1 time series along with NDVI and findings are supported by appropriate ground truth observations and crop cutting experiment (CCE) data. The relative soil moisture change detection is validated with in situ ground truth measurements using Hydraprobe, carried for SCATSAT -1 ascending and descending passes.

Keywords: Crop phenology, gamma-0, rice, sigma-0, soil moisture, vegetation dynamics.

\section{Introduction}

MiCROWAVE missions have an edge over optical missions due to their day-night capability of providing data, as microwave frequency can penetrate clouds as well as vegetation and soil. Scatterometers like ISRO's SCATSAT1 belong to the group of non-imaging radars as they are absolutely calibrated in terms of intensity. While the along-track resolution is given by the antenna gain

\footnotetext{
*For correspondence. (e-mail: chaube@sac.isro.gov.in)
}

pattern, the across-track resolution is achieved by using Ku-band short pulses at $13.515 \mathrm{GHz}$. The relatively low pulse repetition frequency of $193 \mathrm{~Hz}$ leaves sufficient space between consecutive pulses for the radar echo signals to return from the earth's surface to the satellite, which is utilized for onboard calibration and system noise measurements ${ }^{1}$. The signal backscattered by the earth's surface is collected via $1 \mathrm{~m}$ diameter parabolic dish antenna scanning at $20.5 \mathrm{rpm}$ and routed to the SCATSAT1 electronics. The return echo is filtered and sampled in a complex format with a sampling rate of $1.95 \mathrm{MHz}$. The scatterometer output signals are processed onboard with appropriate Doppler correction before they are transmitted to the ground station. As traditional oceanographic application requires wind vector data in continuity with lesser time interval over large swath, SCATSAT-1 is designed to have a systematic coverage with better temporal resolution of 2 days with inner and outer swath of 1400 and $1840 \mathrm{~km}$ respectively in $H H$ and $V V$ polarization.

SCATSAT-1 measures the backscattering coefficient over land surfaces, which is a function of vegetation structure, surface roughness, soil moisture content, incidence angle and dielectric properties of vegetation. Presence of soil moisture can also alter the dielectric property of the land targets ${ }^{2}$. Natural vegetation is characterized by sclerophylls, evergreen shrubs and trees with small, hard or thick leaves that resist water loss trough transpiration. In the arid soil, vegetation is sparse. In the absence of a protective vegetation cover, soil erosion leads to rocky and barren hillsides. Backscatter over land will be different for 'artificial surfaces', 'agricultural areas', 'forest areas', 'wetlands', 'grasslands', 'desert' and 'water bodies'. Kennett and $\mathrm{Li}^{3}$ did the first global analysis of scatterometer over land surfaces based on SEASAT SASS data. Furthermore, various papers have been published on the general possibilities of monitoring land surfaces ${ }^{4}$. Ringelmann et al. ${ }^{5}$ have shown the use of 
QuikSCAT scatterometer for the estimation of planting date of wheat crop. Oza and Parihar ${ }^{6}$ reported the potential of Ku-band scatterometer data of QuikSCAT for rice crop growth stage assessment. In an exhaustive experimental study carried out by Inoue et $a l^{7}$ for rice crop using multi-frequency scatterometer, the observations confirmed the difference in sensitiveness of higher frequency bands $(\mathrm{Ka}, \mathrm{Ku}, \mathrm{X})$ and lower frequency bands $(\mathrm{C}$, L) to rice crop parameters like height, biomass, leaf area, etc.

Soil moisture has a prominent control on the interactions that take place between hydrosphere, biosphere and the atmosphere. Being one of the essential climate variable (ECV), an accurate spatial and temporal variation of soil moisture is a demanding field of research in number of interdisciplinary scientific and operational applications. Presently very few networks are existing both globally as well as in India to provide continuous and reliable soil moisture observations. However, remote sensing observation has proved advantageous to provide both high spatial and temporal resolution of soil moisture $^{8-10}$.

It has also been seen that if the vegetation is optically thin, the effect of soil moisture changes is clearly visible in scatterometer data ${ }^{11}$. In earlier studies ${ }^{12}$, QuikSCAT was evaluated for its sensitivity to soil moisture over an area characterized by a mix of dryland farming and irrigation agriculture using satellite (AMSR-E), aircraft (PLMR) and in situ measured soil moisture. QuikSCAT was found to be reasonably well correlated with the temporal soil moisture variation at regional scale. Relative surface soil moisture from the METOP-A advanced scatterometer (ASCAT) has also been retrieved using change detection approach, which was originally developed for the Active Microwave Instrument flown onboard the European satellites ERS-1 and ERS-2 (ref. 13). Using model parameters derived from eight years of ERS scatterometer data, first global soil moisture maps have been produced from ASCAT data ${ }^{13}$.

Currently available Advanced Microwave Scanning Radiometer (AMSR-2) ${ }^{14}$, soil moisture and ocean salinity $(\mathrm{SMOS})^{15}$ and soil moisture active passive (SMAP) missions $^{16}$ for global soil moisture have limited application due to their low spatial $(\sim 9 \mathrm{~km})$ resolution. Most of the studies for the retrieval of soil moisture utilizing present microwave radiometer/scatterometer observations are being pursued on different disaggregation techniques for this purpose $\mathrm{e}^{17,18}$. Due to high temporal resolution along with all-weather capability and with a legacy of higher retrieval accuracy using radiometer observations, passive-active synergistic techniques have been developed as the basis for NASA's SMAP mission at L-band. However, due to discontinuity of L-band radar of SMAP mission, there is no active-passive sensor combination currently in space that provides high spatial and temporal resolution soil moisture maps.
Therefore, the spatial variability of the SCATSAT-1 backscatter is the reflection of atmospheric-forcing related soil moisture signal and the local variability of vegetation and surface roughness related to differences in soils, topography and land use. The temporal variability of the backscatter is solely due to changes in soil moisture and vegetation phenology. In this paper, SCATSAT1 temporal resolution is exploited to study vegetation dynamics and soil moisture change detection. The rice crop phenology stages such as transplanting, tillering, heading and harvesting (maturity) are identified for kharif and rabi seasons. Estimated soil moisture change using SCATSAT-1 is compared with simulated backscatter using water cloud model (WCM).

\section{Study area and data used}

Land targets (desert, urban area, vegetation, forest, ice covered mountains, etc.) were selected in different parts of India. In India rice is produced in kharif and rabi seasons. For rice phenology study, Punjab, West Bengal and Godavari region of Andhra Pradesh states were taken. Entire Indian land mass was taken for soil moisture estimation while results were validated over Uttar Pradesh and Madhya Pradesh states. Different states taken for the study are shown in Figure 1.

High resolution $\left(0.02^{\circ}\right)$ product of SCATSAT-1 (L4 Ind) backscattering coefficient (sigma-0) are acquired in both polarization ( $H$ and $V$ ) from MOSDAC site (www.mosdac.gov.in). The generation of high resolution back scatter data involves the scatterometer image reconstruction (SIR) resolution enhancement algorithm ${ }^{19-21}$.

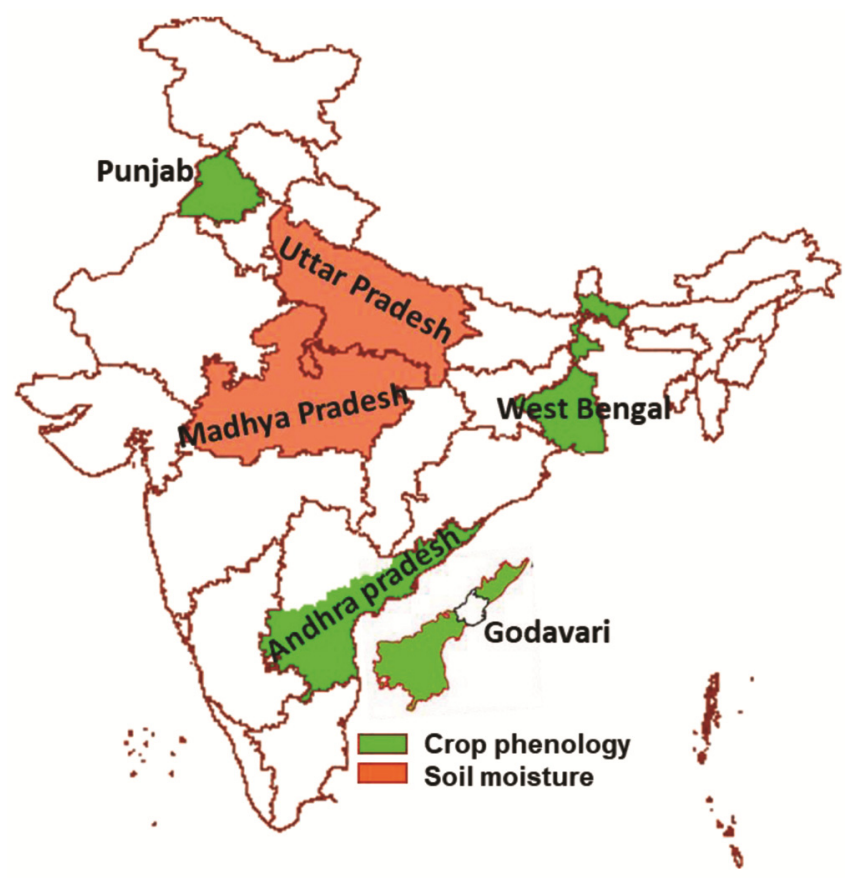

Figure 1. Locations of study sites over India. 
The time series of Ku-band backscatter from SCATSAT-1 was analysed along with rice crop mask and farm level rice planting dates for both seasons of rice crop. Rice crop mask was generated from RISAT-1 and sentinel-1 at Mahalanobis National Crop Forecasting Centre (MNCFC), New Delhi. Farm level planting date details were collected through crop cutting experiment (CCE) conducted by MNCFC, New Delhi ${ }^{22}$. For crop phenology ground truth, the larger rice fields or consecutive fields with same crop were taken as per the resolution of SCATSAT-1 data. The regular field visits were conducted by VIT team in Godavari region.

Soil moisture change can be estimated for entire land mass of India, however, for rigorous analysis of SCATSAT-1 (ascending and descending passes) data and validation purpose Madhya Pradesh (MP) and Uttar Pradesh (UP) were identified. Madhya Pradesh being in the central plain region has been identified to be the best suitable site for soil moisture retrieval, having minimum topographic effect as well as compensating the effect of continuous canopy cover as observed in the coastal region and southern peninsular region ${ }^{23}$. UP situated in the Indo-Gangetic plain is in the low elevated region, but is equally fertile due to river Ganga and its tributary, with availability of variable soil moisture. In both the states different sites were identified based on different soil type and rainfall/irrigation practices that contribute to the variability of soil moisture contents.

In MP, 4 different sites, (a) Sehore (b) Hosangabad (c) Vidisha and (d) Ratibad were selected for ground truth. Each site has 10-12 locations for detailed field observations with an interval of 15 days. Similarly, over UP the ground observations were taken for nearly 60 points around Banaras. The distances between the two sample points are kept more than $2 \mathrm{~km}$ as per grid resolution of SCATSAT-1 level-4 data products to get adequate number of samples. Soil moisture was measured up to soil depth of $10 \mathrm{~cm}$. In situ soil moisture observation date was synchronized with SCATSAT-1 overpass time.

The field parameters measured/recorded during each intensive observation period (IOP) are volumetric surface soil moisture, soil temperature, dielectric constant and electric conductivity along with crop conditions. Apart from the distributed soil moisture observation with hand held instrument during IOP, continuous soil moisture observations were recorded by the hydraprobe stations installed by SAC, ISRO, Ahmedabad. The hydraprobe stations are located at Lat/Lon 22.69/77.74 in Madhya Pradesh and at Lat/Lon 25.26/82.99 in UP.

\section{Methodology}

SCATSAT-1 fine resolution $2 \mathrm{~km}$ products were used to generate time series for various types of land features. The GT location of various land targets were overlaid on
SCATSAT-1 data for time series generation at that location.

For rice phenology two approaches are presented in this paper; the first approach uses statistical modelling to ascertain different phenology stages and the second approach uses a polynomial fit on the SCATSAT-1 temporal measurements to compare with rice morphology life cycle.

For first approach, the backscatter time series was analysed with MODIS NDVI, Water Index (WI) and WI anomaly (1st derivative of WI) for statistical modelling over Godavari region. Figure 2 shows the different combination of data used to find each stage. In the second approach, map of rice transplanting dates were generated over Punjab in kharif season (2017) and over West Bengal in rabi season (2016-2017) using the polynomial fit of time series backscatter in vertical polarization (SV). The backscatter coefficient (sigma-0) is taken in both horizontal $(\mathrm{SH})$ and vertical polarization (SV) from 1 May 2017 to 31 October 2017 over Punjab and from 15 November 2017 to 30 April 2018 over West Bengal. The CCE points and the state boundaries were overlaid to extract the time series $\mathrm{SH}$ and $\mathrm{SV}$ over rice pixel. Kharif rice mask of Punjab and rabi rice mask of West Bengal were resampled to SCATSAT-1 resolution $(2 \mathrm{~km})$ and applied to the respective state to identify the rice area. The time series SV and SH data over resampled rice pixel of each state were analysed to understand the signature of rice crop in terms of sigma- 0 . Temporal averaging of the data was done at 7-day and 15-day to smooth out the noise in the dataset and also to find out the best temporal mean for generating the rice phenology. ISODATA classification scheme was applied to cluster rice pixels with homogenous planting date and rice ecosystem. The average signature of each class was plotted and polynomial curve was fitted to find out the planting. The dates were validated with the ground planting date information through CCE.

For the soil moisture study, enhanced resolution $2 \times 2$ $\mathrm{km}$ data product of SCATSAT-1 (level-4), has been used for sensitivity analysis of gamma-0 for soil moisture change detection. Both ascending and descending orbit

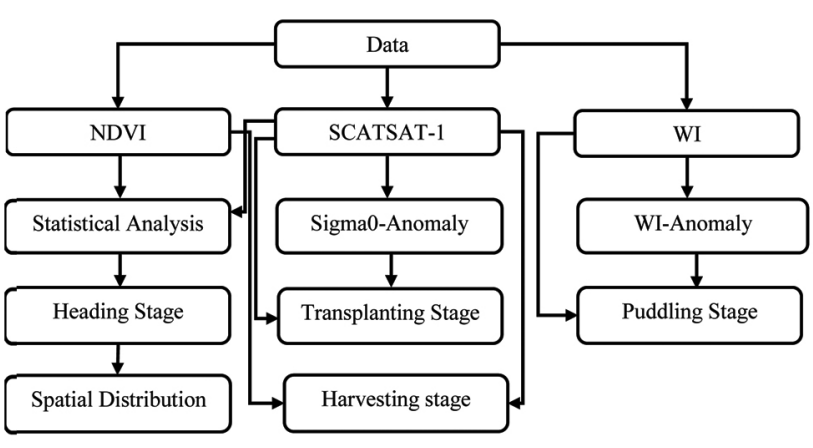

Figure 2. Methodology for rice phenology estimation. 
pass datasets have been used to analyse the effect of satellite passes over soil moisture variability for UP and MP.

Over MP, the time series and correlation analysis between measured in situ soil moisture and sigma-0 was carried out. In order to analyse the effect of vegetation on sigma-0 values the MODIS NDVI data has been used (www.vedas.sac.goc.in) over Madhya Pradesh. However, simulated backscatter using Water Cloud Model has been compared with field data in UP. As an input parameter in WCM, the leaf area index data was incorporated from Copernicus land service of SPOT-VGT, PROBA-V sensor with a spatial resolution of $1 \mathrm{~km}$.

\section{Results and discussion}

Over the land surfaces the main geophysical parameters influencing the backscattered signal are soil moisture, surface roughness and vegetation. Various natural processes act on different space and time scales on these parameters. These parameters act on different time scales: surface soil moisture on scales of one day or less, vegetation on scales from several days to weeks, and surface roughness should in general be stable.

Backscatter from bare soil surfaces is sensitive to surface height variations on scales comparable to the wavelength of the radar system. The surface roughness of the soil surface ranges from millimetres to decimetres. The surface height may vary considerably over short distances but within $2 \mathrm{~km}$ resolution cell, little spatial dependency ${ }^{24}$ can be assumed. Soil formation processes usually act on time scales from decades to several thousands of years ${ }^{25}$ and therefore, for the short time span considered in this study, surface roughness should be expected to be a relatively stable factor over time. Nevertheless, on relatively short time scales of 2 days, surface roughness characteristics may be changed by human activities like tillage of agricultural fields. Subsequent rainfall may smooth the so disturbed surface ${ }^{26,27}$. Vegetation canopy in different phenology state can act as rough or smooth surface.

To focus on the processes that are important at the measurement scale of $2 \mathrm{~km}$, soil moisture will have more impact on backscatter as compared to surface roughness on a pure target. Pure target means that the same feature is extended over larger area. Resolution cell filled with mixed targets will have ambiguous backscatter, i.e. contribution from more target types.

\section{Backscatter seasonal trend for various land targets}

Different land targets are selected keeping in the mind the resolution of SCATSAT-1. The main parameters affecting the backscattering signal over land surfaces are the moisture content in the top few centimetres of the soil, the roughness of the soil surface, and the absorption and scattering characteristics of the vegetation canopy.

For sand and barren land temporal backscatter variation is shown in Figures 3 and 4. The processes by which soils are formed are known as pedogenic processes, including additions, transformations, transfers and losses ${ }^{28}$. The factors controlling these processes encompass climate, organisms, relief, parent material and time. The structure (e.g. horizon differentiation) and the composition (e.g. texture, organic matter content) of soils are determined by these pedogenic processes, and hence also surface roughness. For example, poorly developed soils with frequent rock outcrops and gravel surface such as lithosols can be expected to have a rougher soil surface in terms of radar backscatter than highly developed soils. Consequently, on larger scales, surface roughness patterns should reflect differences in climate, vegetation, relief and parent material.

In Figures 3 and 4, backscatter variation in $H H$ and $V V$ polarization is due to the seasonal variation in the soil moisture. The dry and wet desert sand has $5 \mathrm{~dB}$ variation in $\sigma_{0}$ whereas barren land has maximum variation of $2 \mathrm{~dB}$. The soil moisture content changes the dielectric constant of the land surface which affects $\sigma_{0}$.

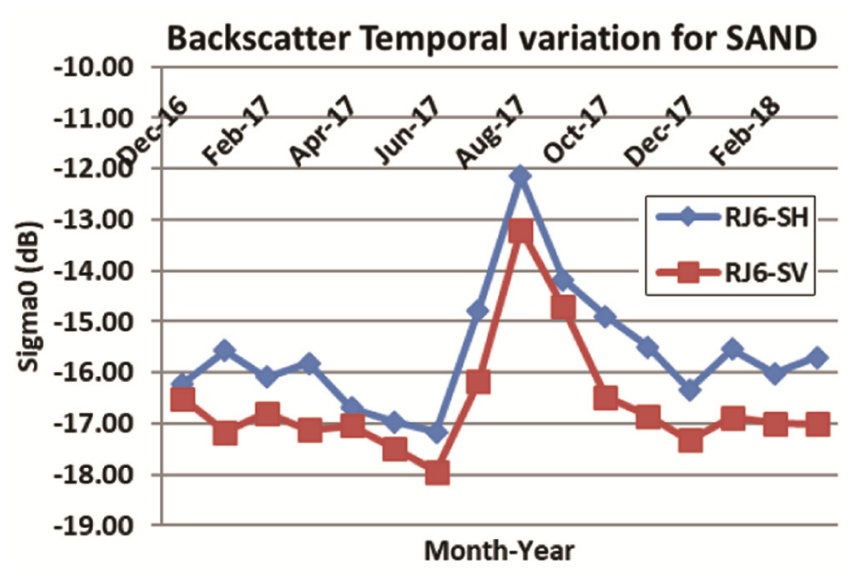

Figure 3. Ku-band sensitivity for sand.

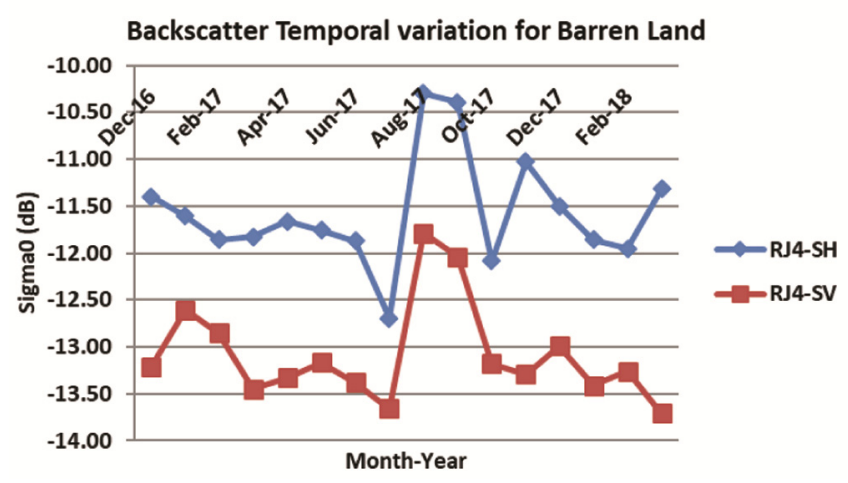

Figure 4. Ku-band sensitivity for barren land. 
The structure of vegetation strongly influences the scattering characteristics from vegetated terrain. Vegetation can be broadly classified as translucent and nontransparent types. Smaller plant, non-irrigated vegetation, natural grass land can be taken as translucent and the 'broad-leaved forest', 'coniferous forest', 'mixed forest', and 'sclerophyllous vegetation' can be considered as nontransparent vegetation for $\mathrm{Ku}$-band interaction.

Figures 5 and 6 depict the SCATSAT-1 temporal backscatter for different forest locations and vegetation in different states. The dominant mechanisms contributing to the backscattering coefficient of surfaces covered by vegetation are volume scattering in the vegetation canopy and surface scattering from the underlying soil surface. The status of vegetation depends on anthropogenic activities as well as on moisture/rainfall patterns. Moisture has seasonal and inter-annual variability. The seasonal variation of the $\sigma_{0}$ is due to vegetation growth and senescence.

The urban area is unique and evolving over time. The backscatter response from urban area, man-made structures have maximum backscatter value depicted in Figure 7 as compared to other land classes shown in Figures 1-7. The regular gridded road and building orientation acts as dihedral corner reflector. Density of buildings is proportional to signal strength. Temporal variation of backscatter over different water bodies is shown in Figure 8. Effect of local wind is evident in the backscatter variation.
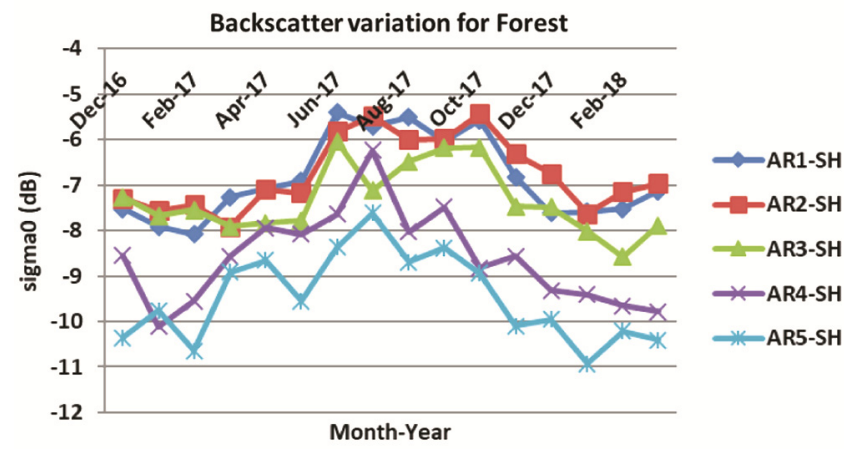

Figure 5. Ku-band sensitivity for forest.
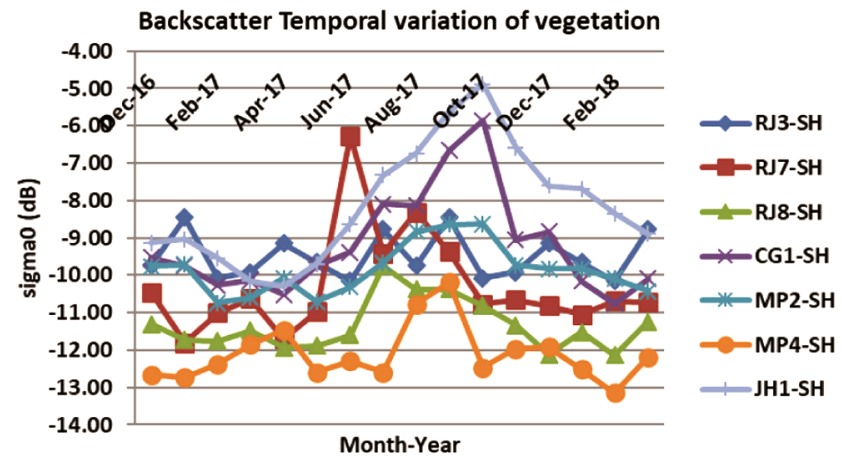

Figure 6. Ku-band sensitivity for vegetation.

\section{Rice phenology assessment}

Rice crop phenology stages along with SCATSAT backscatter and NDVI are shown in Figure 9. The first approach, statistical modelling is used to identify rice phenology in Godavari region and results are depicted in Figures 10-14. The second approach of polynomial fit is used for Punjab and West Bengal kharif and rabi rice, results for which are shown in Figures 15-18. The SCATSAT- 1 sigma- 0 was analysed with sigma- 0 anomaly (1st derivative of sigma-0), NDVI and water index data for identifying various phenology stages of rice crop in Godavari region in Andhra Pradesh. The sigma-0 and NDVI time series for full rice crop cycle is shown in Figure 9. Figure 10 depicts the sigma- 0 and its anomaly, the first cross section of the two is taken to identify the transplanting stage.

Figure 11 depicts the puddling stage, i.e. fields prepared in the Godavari region for the transplanting of rice. Puddling stage is estimated using SCATSAT-1 backscatter and the water index data. SCATSAT-1 backscatter and NDVI data are used for identifying rice phenology stages such as transplanting, heading and maturity. Figures 12-14 show the transplanting, heading and harvesting (maturity) stage for rabi rice in the Godavari region, using methodology shown in Figure 2.

In Punjab, kharif rice season, backscatter increased from a low backscatter with the flooded/transplanted

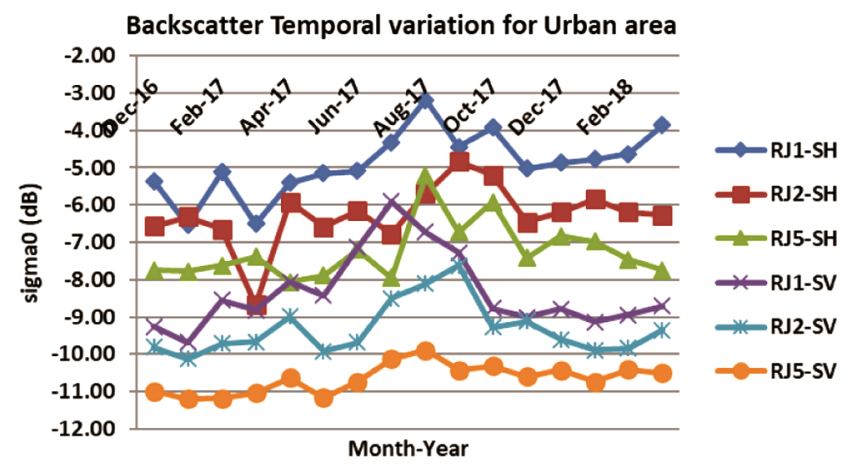

Figure 7. $\mathrm{Ku}$-band sensitivity for urban.

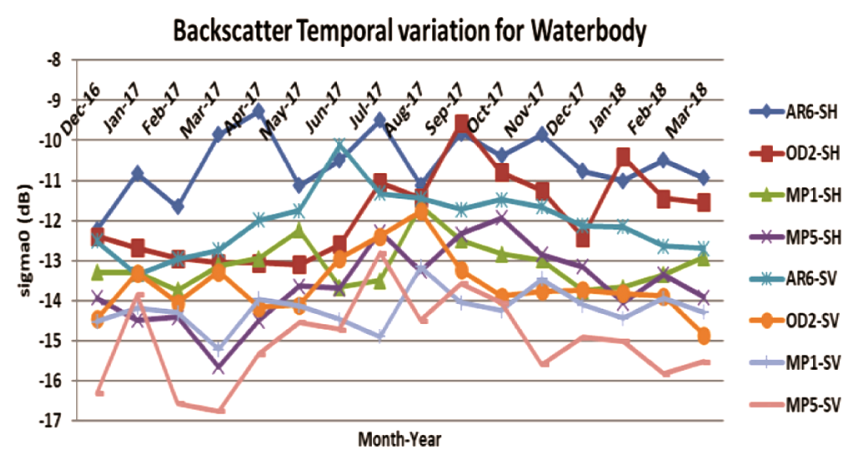

Figure 8. Ku-band sensitivity for area waterbody. 
stage (mid-June) till last week of July and then registered a steady decline till early mid-September. The backscatter minima of the temporal signature were observed at this stage. Backscatter thereafter again increased up to the maturity stage. The sigma-0 from transplanting stage to maturity stage varied from around -10.6 to $-12.5 \mathrm{~dB}$ in vertical (SV), while from -11 to $-13.5 \mathrm{~dB}$ in horizontal (SH) polarization. The time series plots of sigma-0 in $V V$ polarization in Punjab during kharif season and West Bengal during rabi season with contrasting rice ecosystem are shown in Figures 15 and 16 respectively.

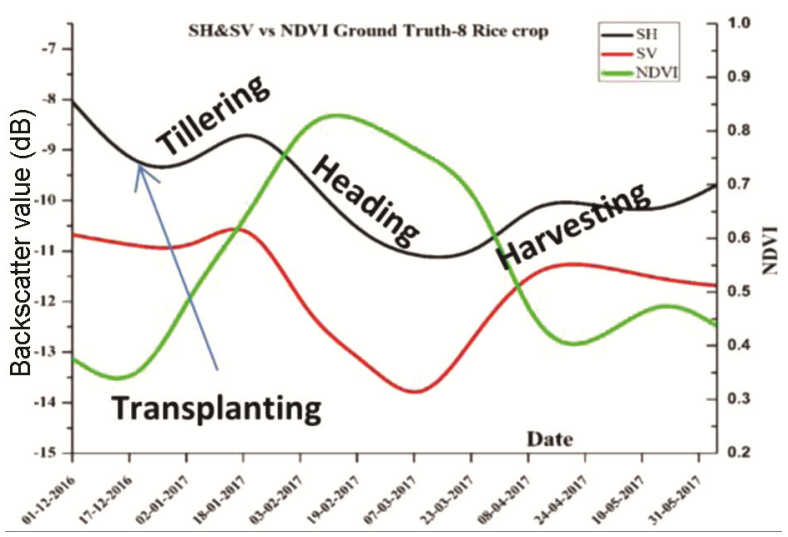

Figure 9. Rice crop phenology.

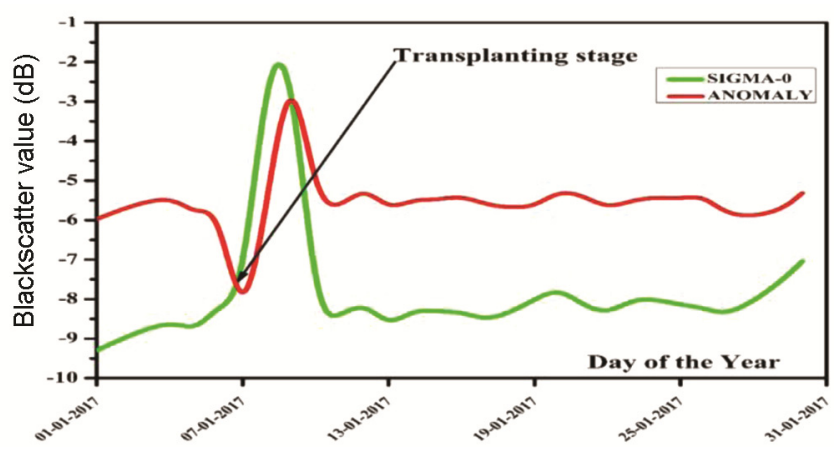

Figure 10. Transplanting stage.

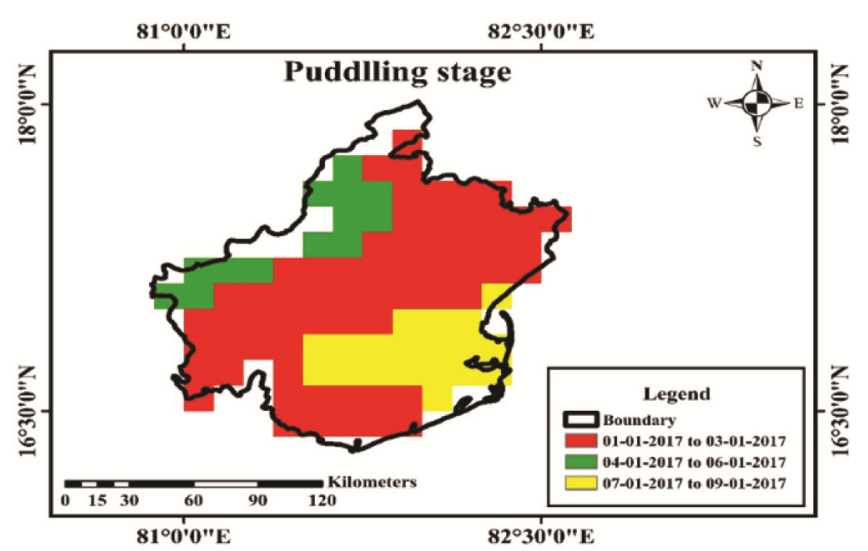

Figure 11. Fields ready for rice transplanting.
The time series sigma- 0 showed a dual peak (one at maximum tillering stage and other at grain filling stage) and dual minima (one just prior to transplanting and one at the maximum LAI stage) in both states. This may be due to the change in roughness of the rice morphology such as increase in roughness after the first minima at flooding stage (transplanting) due to increase in tiller number till the maximum tillering stage where the curve

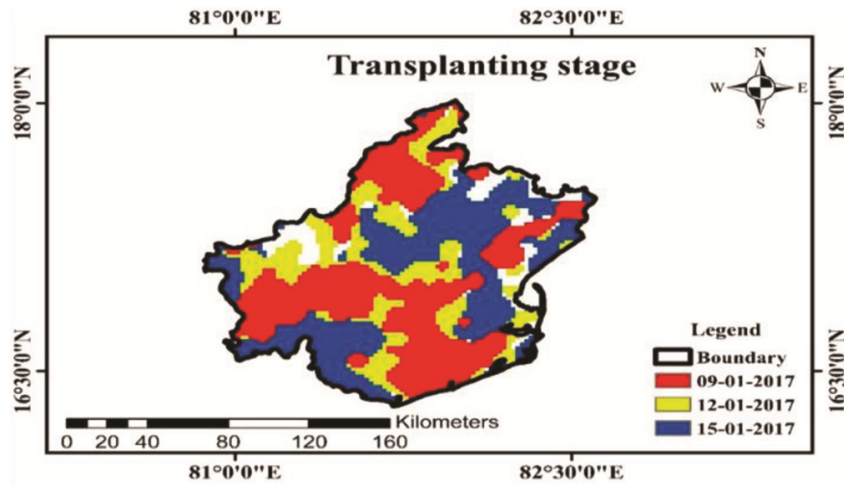

Figure 12. Transplanted rabi rice.

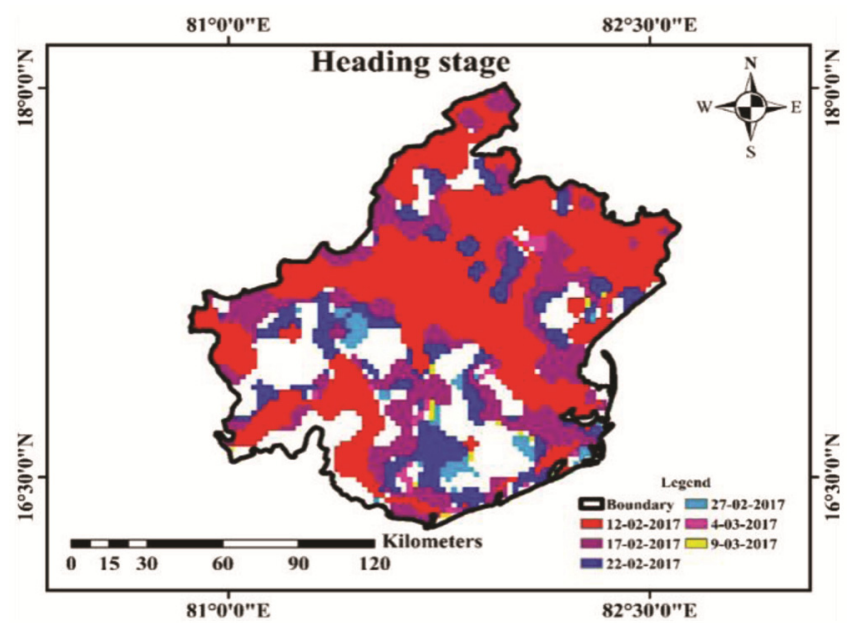

Figure 13. Heading stage of rabi rice.

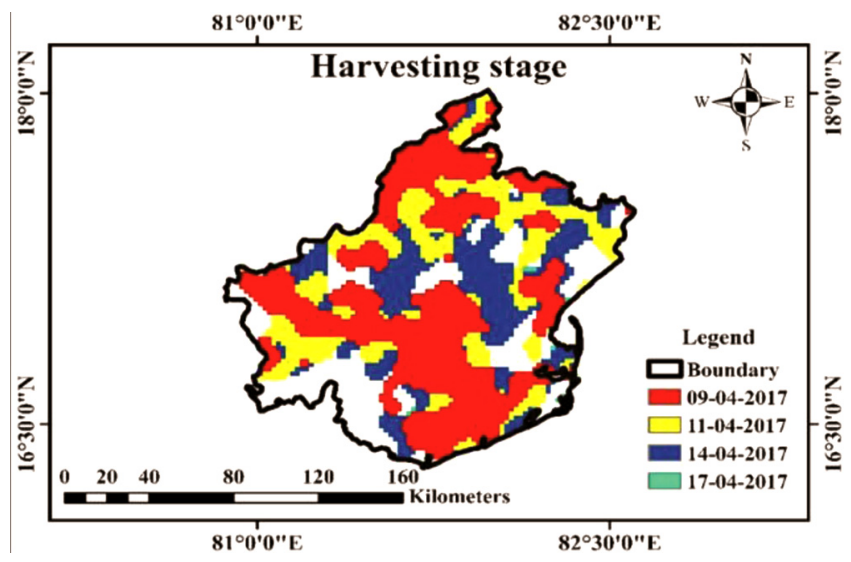

Figure 14. Harvesting stage of rabi rice. 

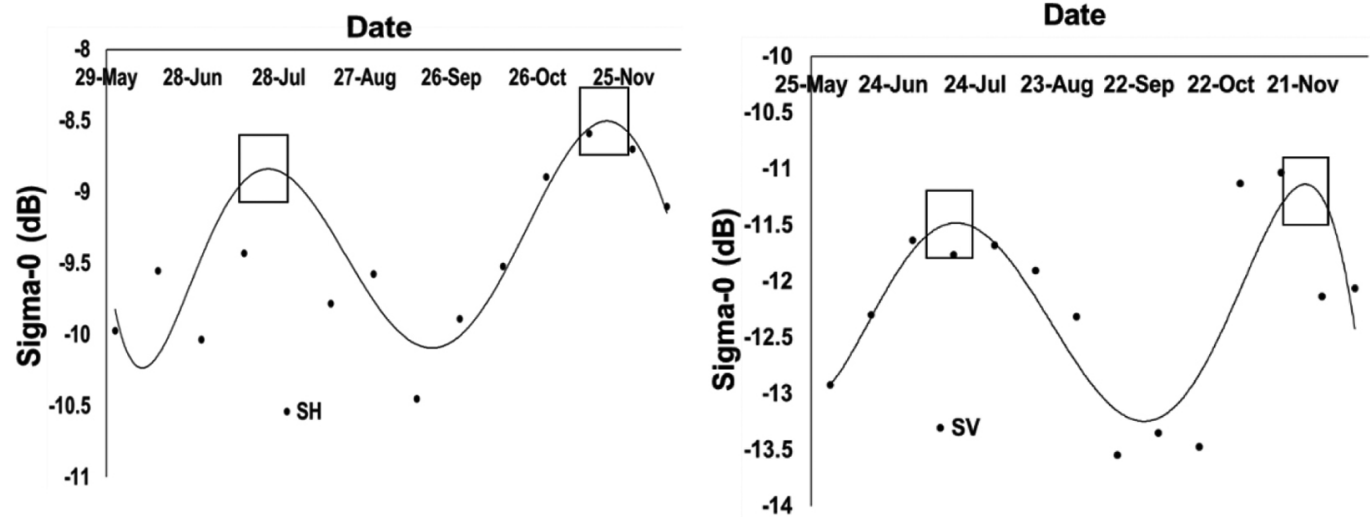

Figure 15. Temporal profile of sigma-0 ( $S H$ and $S V$ ) over rice areas of Punjab in kharif season.
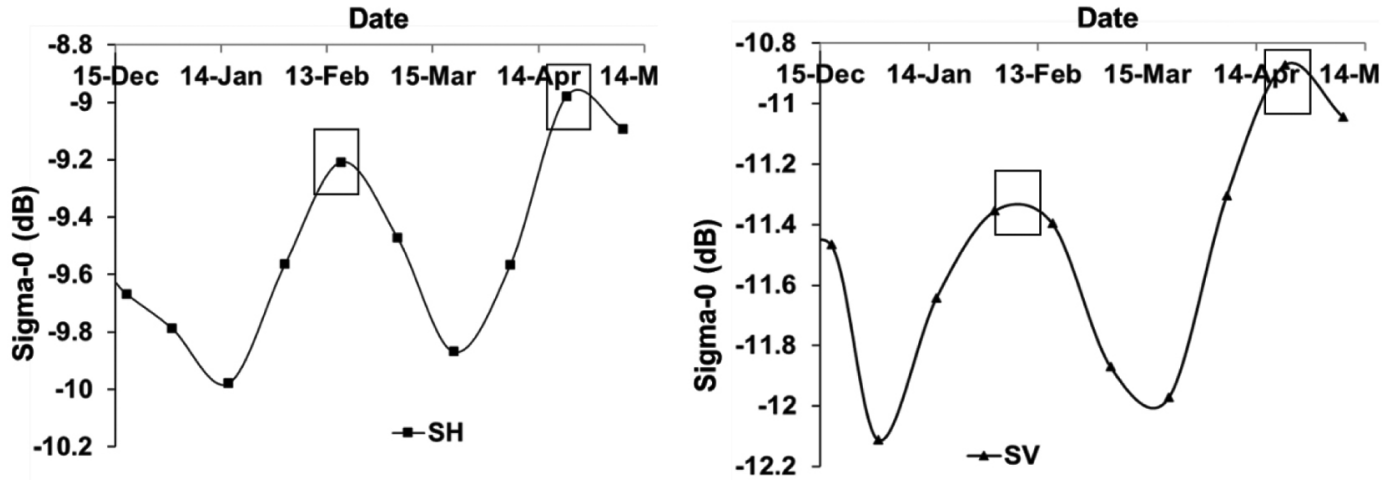

Figure 16. Temporal profile of sigma-0 (SH and $S V)$ over rice areas of West Bengal in rabi season.

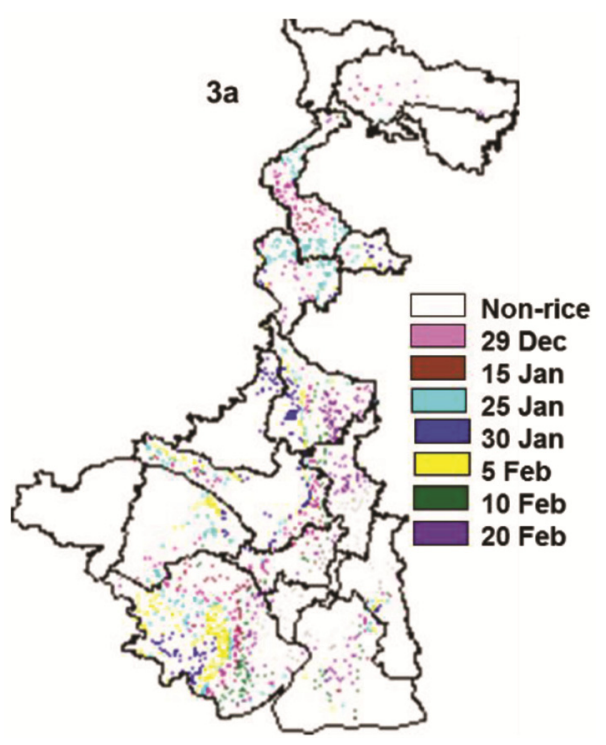

Figure 17. Planting date of rabi rice in West Bengal.

reaches the first maxima; thereafter increase in smoothness due to leaf coverage resulted in the second minima at peak LAI stage, then increase in roughness due to development of panicles till the grain filling stage thus reaching the second maxima and then reduction in roughness due to covering of canopy with the rice grains till

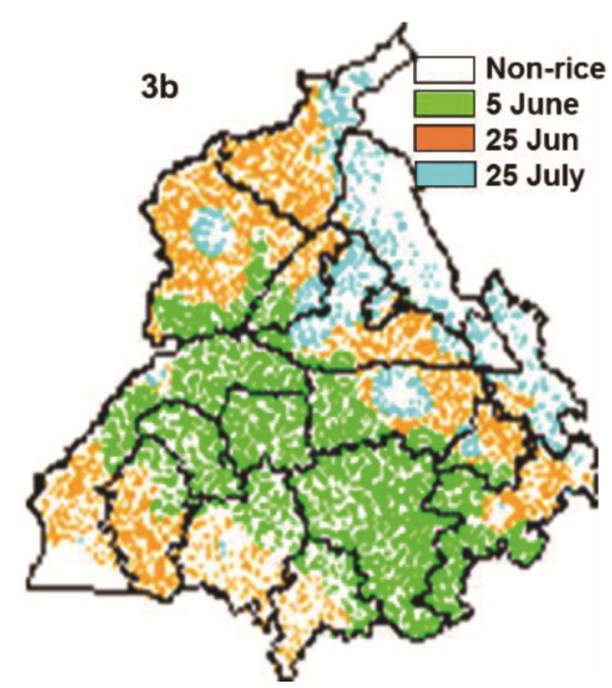

Figure 18. Planting date of kharif rice in Punjab.

harvest. This is in contrast to the C-band response, where the backscatter increases with crop growth. The pattern matched well with the observations reported by other researchers using the $\mathrm{Ku}$-band scatterometer data from QuickSCAT ${ }^{6}$. Vertical polarized time series is used to estimate rice planting date. Planting date of rabi rice over West Bengal is given in Figure 17 and that for kharif rice over Punjab state is given in Figure 18. 


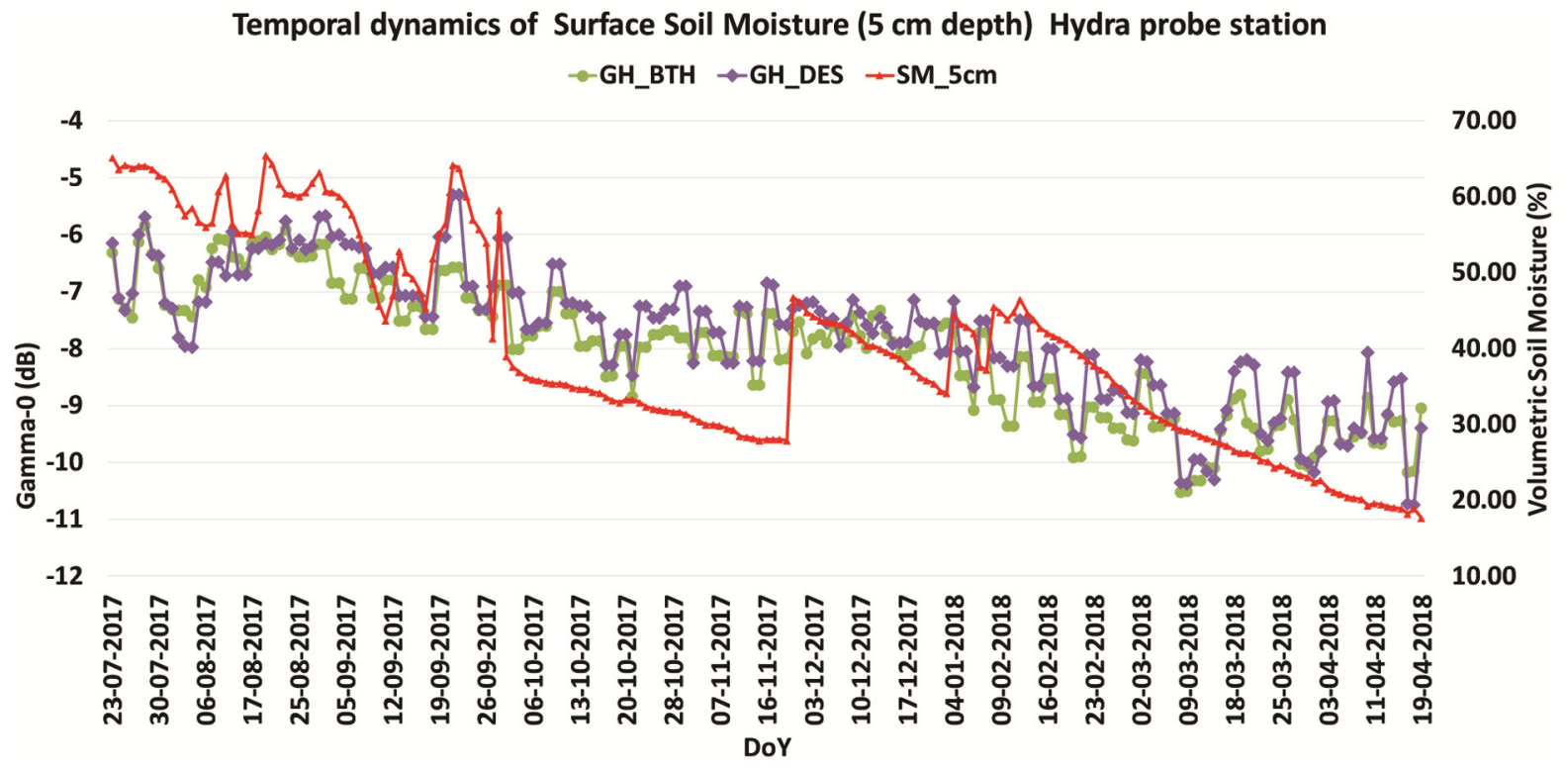

Figure 19. Time series of surface soil moisture from Hydraprobe station data and SCATSAT-1 gamma- $0 H H$ for ascending and descending node.

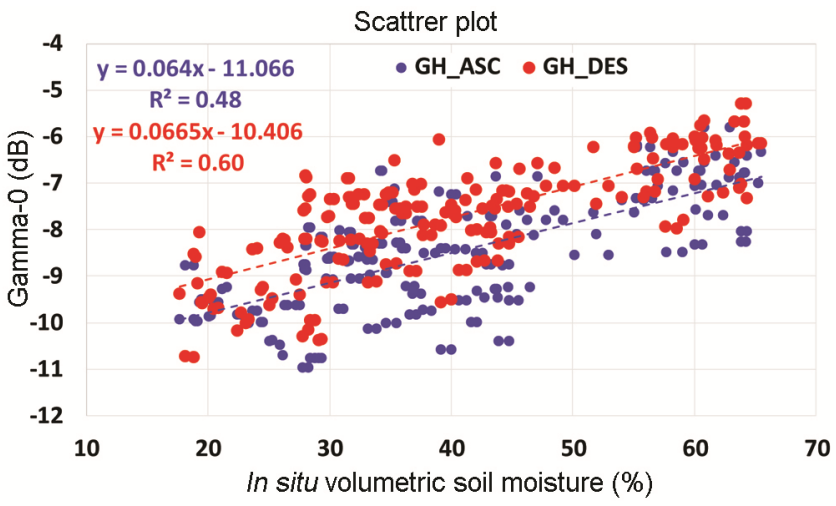

Figure 20. Scatter plot for soil moisture (Hydraprobe station) versus backscatter.

For West Bengal seven classes were obtained showing variable planting dates starting from 29 December to 20 February (Figure 17). GT data shows planting date varied from the first week of January to fourth week of February. In Punjab three different classes were obtained with variable planting date using sigma-0 (SV). The planting dates varied from 5 June to 25 July 2017 (Figure 18). Field data from CCE showed that planting date of rice in Punjab during kharif season ranged from 5 June to 27 July.

\section{Soil moisture}

The results of the preliminary analysis for both MP and UP have been discussed in this section. Figure 19 shows the time series of SCATSAT-1 gamma-0 in HH polarization for both ascending and descending node with in situ soil moisture at $5 \mathrm{~cm}$ depth from Hydraprobe station at ZARS, Hoshangabad from 22 July 2017 to 19 April 2018. The dynamic range of soil moisture is observed to be between $\sim 20 \%$ and $60 \%$ for the entire period of study. The gamma- 0 value varies between $-10 \mathrm{~dB}$ to $-5 \mathrm{~dB}$. The temporal pattern in backscatter signal is observed to follow the trend in soil moisture. Some anomalies are observed near the date of installation (22 July 2017). During rainy season (July-September) the soil moisture being high which leads to high dielectric constant, resulting in a high backscatter coefficient. However, during this time the study region is covered with crop and the canopy is fully covered. The amount of vegetation material of the canopy will determine the attenuation and absorption along the path. As monsoon starts to withdraw after September the soil moisture starts decreasing, the gmma-0 also shows a decreasing trend. In December there is a sudden increase in soil moisture which may be due to irrigation of the crop field for wheat cultivation. Between December to January even though daily soil moisture decreases, gradually the gamma- 0 value shows only marginal change. This may be due to the fact that for $\mathrm{Ku}$-band the signal for a fully covered canopy is mainly attributed to the vegetation water content instead of soil water content. After February not only soil moisture decreases, the gamma- 0 value also shows a decreasing trend, because at this stage the water content of the crop also decreases.

Figure 20 shows the correlation between soil moisture and backscatter co-efficient for both ascending and descending passes. From Figure 20, it is observed that the correlation of soil moisture with backscatter co-efficient is more for descending pass than that of the ascending 
pass. This may be due to the diurnal evaporation of surface soil moisture during the day.

Simulated sigma-0 using WCM has been compared with the SCATSAT-1 sigma-0 with number of input parameters for the study site over $\mathrm{UP}^{29}$ for sensitivity study and validation prior to soil moisture retrieval. The comparison is shown in Figures 21 and 22 for dense and sparse vegetation condition. From the figure it is seen that SCATSAT-1 backscatter has a good match with simulated WCM backscattering with dense vegetation cover. This backscattering difference between SCATSAT-1 and the simulated one can be attributed to the vegetation cover.

\section{Conclusion}

Backscatter on land depends on vegetation, surface roughness and soil moisture; a great deal is required to distinguish the individual effects. The spatial variability of the SCATSAT-1 scatterometer signal is caused by atmospheric forcing (precipitation, evapo-transpiration)

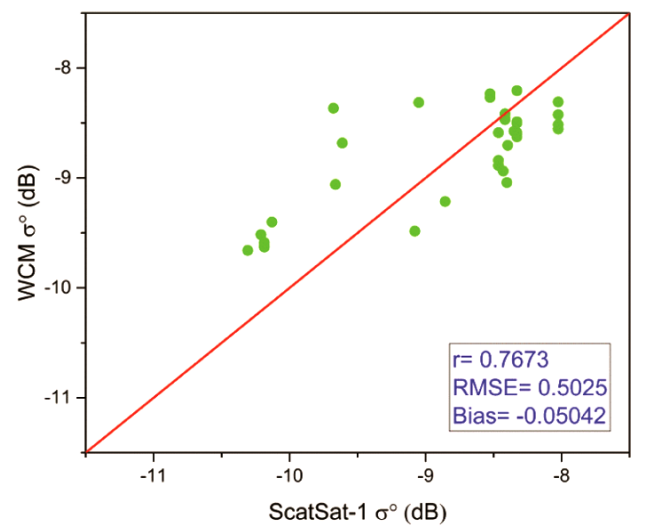

Figure 21. SCATSAT-1 and simulated WCM sigma-0 with dense vegetation cover $^{14}$.

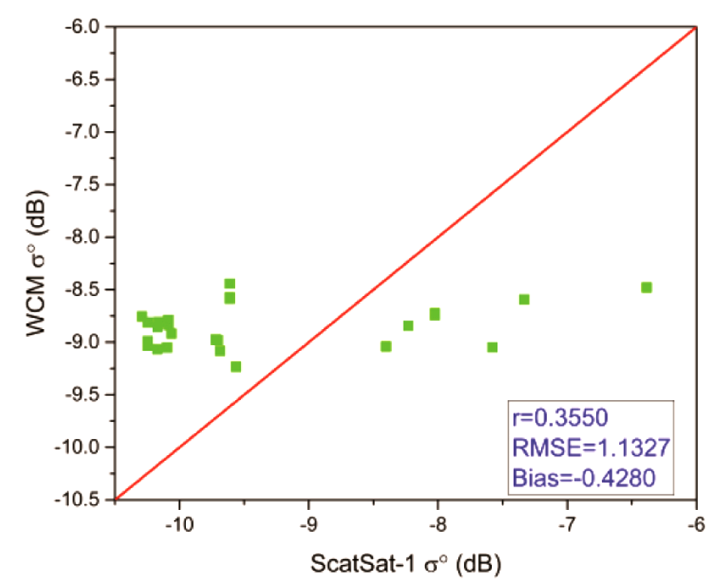

Figure 22. SCATSAT-1 and simulated WCM sigma-0 with sparse vegetation cover ${ }^{14}$. of soil moisture, patterns of vegetation as a function of soils, landforms and land use, and by changes in the microrelief related to soil formation factors such as climate, vegetation and topography.

The main parameters affecting the backscattering signal over land surfaces are the moisture content in the top few centimetres of the soil, the roughness of the soil surface, and the absorption and scattering characteristics of the vegetation canopy. All these parameters vary at different scales, and a crucial point for the correct interpretation of the SCATSAT-1 scatterometer signal is to have a good understanding of the processes that control the various parameters at the observation scale $(2 \mathrm{~km})$. The changes in the surface soil moisture content cause a high variability of the SCATSAT-1 signal at short time scales (minutes to days), changes in vegetation at time scales from days to weeks, and surface roughness should in general be expected to be stable over time. The assumption is that temporal changes in the backscattering characteristics are solely due to changes in soil moisture and vegetation, keeping in mind that in some situations this assumption may not be strictly valid.

This paper highlights the results of $\mathrm{Ku}$-band scatterometer data from SCATSAT-1 for rice planting date and phenology. The time series backscatter (both in horizontal and vertical polarization) of rice from transplanting to maturity stage showed characteristic dual peak profile. The various rice phenology stages estimated for Godavari region agreed well with the ground truth observations. The backscatter minima coincided with the period of maximum leaf area index. The classification of the time series sigma-0 (SV) resulted in 7 classes of planting dates in rabi rice of West Bengal while three classes of planting date in kharif rice of Punjab. The range of planting date derived from the time series $\mathrm{SV}$ in both the states and seasons matches with the range of planting dates collected in the CCE from the respective state. This study showed the capability of Ku-band backscatter for rice phenology estimation. SCATSAT-1 soil moisture change detection agrees well with the in situ hydraprobe measurements. This data can be used for development of different disaggregation techniques, making synergetic use of SMAP/AMSR2 brightness temperature data in implementing the active-passive retrieval algorithms.

Scatterometer data can be utilized for vegetation mapping, vegetation classification, deforestation, urban change detection, relative soil moisture estimation, drought and flood monitoring. The preliminary analysis shows that number of challenges are still required to be resolved by the scientific community, which will allow deriving accurately products with the help of SCATSAT1 data for terrestrial applications. It is also obvious that to satisfy the requirements of SCATSAT-1 information for many practical applications, efforts should be made towards the investigation of the synergistic use of SCATSAT-1 with other co-orbiting satellites for different 
applications. In future, polarimetric scatterometry will help to get more insight in land applications.

1. Attema, E. P. W., The active microwave instrument on-board the ERS-1 satellite. Proc. IEEE, 1991, 79(6), 791-799.

2. Schanda, E., Physical Fundamentals of Remote Sensing, Springer Verlag, Berlin Heidelberg, etc., 1986, p. 187.

3. Kennett, R. G. and Li, F. K., Seasat over-land scatterometer data, part I: global overview of the Ku-band backscatter coefficients. IEEE Trans. Geosci. Remote Sensing, 1989, 27, 592-605.

4. Messeh, M. A. and Quegan, S., Variability in ERS scatterometer measurements over land. IEEE Trans. Geosci. Remote Sensing, 2000, 38, 1767-1776.

5. Ringelmann, N., Scipal, K., Bartalis, Z. and Wagner, W., Planting date estimation in semi-arid environments based on $\mathrm{Ku}$-band radar scatterometer data. In IGARRS'2004, Anchorage, USA, 2004.

6. Oza, S. R. and Parihar, J. S., Evaluation of Ku-band QuikSCAT scatterometer data for rice crop growth stage assessment. Int. J. Remote Sensing, 2007, 28(16), 3447-3456.

7. Inoue, Y., Kurosu, T., Maeno, H., Uratsuka, S., Kozu, T., Dabrowsk-Zielinska, K and Qi, J., Season-long daily measurements of multi-frequency ( $\mathrm{Ka}, \mathrm{Ku}, \mathrm{X}, \mathrm{C}$, and $\mathrm{L})$ and fullpolarization backscatter signatures over paddy rice field and their relationship with biological variables. Remote Sensing Environ., 2002, 81, 194-204.

8. Schmugge, T., Remote sensing of soil moisture. In Hydrology Forecasting (eds Anderson, M. G. and Burt, T. P.), Wiley, New York, 1985, pp. 101-124.

9. Zhao, W. and Li, Z. L., Sensitivity study of soil moisture on the temporal evolution of surface temperature over bare surfaces. Int. J. Remote Sensing, 2013, 34, 3314-3331.

10. McCabe, M. and Wood, E., Scale influences on the remote estimation of evapotranspiration using multiple satellite sensors. Remote Sensing Environ., 2006, 105(4), 271-285.

11. Wagnar, W., Noll J. Borgeaud and Rott, H., Monitoring soil moisture over the Canadian Prairies with ERS scatterometer. IEEE Trans. GeoSci. Remote Sensing, 1997, 37(1), 206-216.

12. Iliana Mladenova, Venkat Lakshmi, Jeffrey P. Walker and David G. Long, An assessment of QuikSCAT Ku-band scatterometer data for soil moisture sensitivity. IEEE Geosci. Remote Sensing Lett., 2009, 6(4), 640-643.

13. Bartalis et al., Initial soil moisture retrievals from Metop-A advanced scatterometer (ASCAT). Geophys. Res. Lett., 2007, 34, L20401.

14. Bindlish et al., Development and validation of the GCOMW AMSR2 soil moisture product, IGARSS 2016, pp. 1647-1650.

15. Kerr, Y. H., Waldteufel, P., Wigneron, J. P., Martinuzzi, J., Font, J. and Berger, M., Soil moisture retrieval from space: the soil moisture and ocean salinity (SMOS) mission. IEEE Trans. Geosci. Remote Sensing, 2001, 39, 1729-1735.

16. Entakhabi et al., Soil moisture active and passive (SMAP) mission. Proc. IEEE, 2010, 98(5), 704-716.
17. Das, N. et al., An algorithm for merging SMAP radiometer and radar data for high resolution soil moisture retrieval. IEEE Trans. GeoSci. Remote Sensing, 2011, 49(5), 1504-1512.

18. Ujjwal Narayan and Venkat Lakshmi, A simple method for spatial disaggregation of radiometer derived soil moisture using higher resolution radar observations. Progress in Electromagnetics Research Symposium 2005, Hangzhou, China, 22-26 August.

19. Long, D. G. and Daum, D., Spatial resolution enhancement of SSM/I data. IEEE Trans. Geosci. Remote Sensing, 1997, 36, 407417.

20. Jalpa, M. and Kirti, P., Generation of high resolution sigma-0 through algebraic reconstruction, Scientific report/SAC/SIPA/ DPSG/AIPD/TN-09/Jul., 2015.

21. Jalpa, M., Evaluation of OSCAT high resolution sigma-0 products generated at SAC Scientific report, SAC/SIPG/MDPD/SCATDP/TN-01/Mar. 2016, 2016.

22. Ray, S. S. and Dubey, S., Space technology use in crop insurance. In E-Agriculture in Action: Drones for Agriculture (ed. Sylvester, G.), Food and Agriculture Organization of the United Nations and International Telecommunication Union. Bangkok, 2017, pp. 6570 .

23. Chaurasia et al., Assessment of the AMSR-E soil moisture product over India. Int. J. Remote Sensing, 2011, 32(23), 7955-7970.

24. Lehrsch, G. A., Whisler, F. D. and Römkens, M. J. M., Spatial variation of parameters describing soil surface roughness. Soil Sci. Soc. Am. J., 1988, 52, 311-319.

25. Wild, A., Soil and the Environment: An Introduction, Cambridge University Press, Cambridge, 1993, p. 287.

26. Lehrsch, G. A., Whisler, F. D. and Römkens, M. J. M., Soil surface roughness as influences by selected soil physical properties. Soil Till. Res., 1987, 10, 197-212.

27. Lehrsch, G. A., Whisler, F. D. and Römkens, M. J. M., Selection of a parameter describing soil surface roughness. Soil Sci. Soc. Am. J., 1988, 52, 1439-1445.

28. Ellis, S. and Mellor, A., Soils and Environment, Routledge, London, 1995, p. 364.

29. Ujjwal Singh, P. K. et al., Assessment of ScatSat-1 backscattering by using the state of the art water cloud model. International Conference on Geomatics in Civil Engineering (ICGCE-2018), 5-6 April 2018, IIT Roorkee, 2018.

ACKNOWLEDGEMENTS. We thank Shri D. K. Das, Director SAC for his keen interest and encouragement for the application of scatterometer data from SCATSAT-1 for crop research. Our sincere thanks are due to Dr D. D. Rajkumar, EPSA and project coordinator, SCATSAT-1 utilization project for his constructive suggestion for proper utilization of the SCATSAT-1 sigma-0 product for various applications. We acknowledge the SCATSAT-1 data product team of SAC for the high resolution $\mathrm{Ku}$ band scatterometer data from SCATSAT-1.

doi: $10.18520 / \mathrm{cs} / \mathrm{v} 117 / \mathrm{i6} / 1022-1031$ 